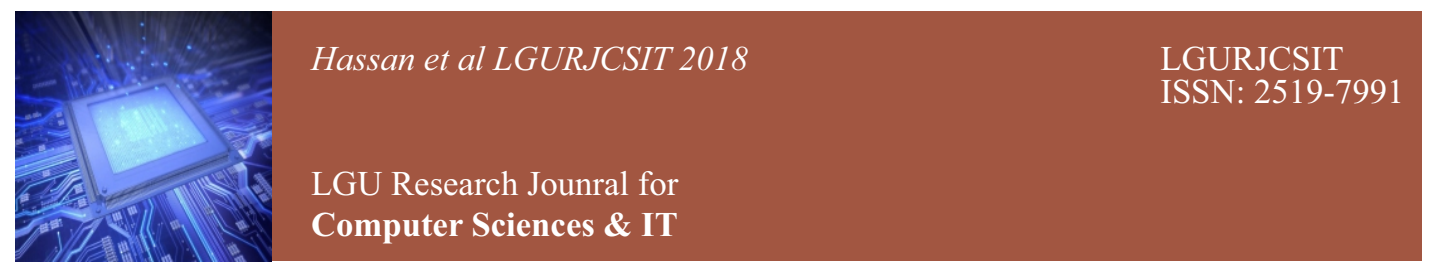

\title{
Improved Software Requirement process for Software Industries
}

Taimoor Hassan, Muhammad Zulkif Hasan, Zaka Ullah

Department of Computer Science, Lahore Garrison University, Lahore, Pakistan taimoorhassan9@yahoo.com1zulkifl.hasan@lgu.edu.pk2zakaullah@lgu.edu.pk

\section{Abstract}

In the software system development, requirement engineering plays a great role because system successfulness depends on it. If the requirements are clear and unambiguous in every aspect then the system will be developed error free. A number of clients that are not educated and illiterate, then in this scenario, the given requirements are not clear and full of ambiguous. In this paper, we proposed a method to resolve this problem in the shape of break the requirements, filter it (separate the necessary and un-necessary requirements), break into little bits, numbering them and prioritize them, after it is documented, the requirement that is very helpful for current and future changing in software system and finally shift to the development team for develop the project. We will apply this proposed method on case study as experimental to find out the definite and relevant results

Keywords: Requirement Engineering, Natural Language, Requirement Management, Software System

\section{INTRODUCTION}

In the classical approach of software development; in the product development of design phase a few requirements are used as input. Within software engineering, Software requirement engineering is a field that maintain the requirements of company holders and solved it with the help of software. A process optimization and development of a product, for the need of specific design, development process and product, functional and physical requirement is an individual document that must be able to perform. For the design, service or product, material, several requirements specifications must be satisfied to complete the task. A term requirement has been in use in the software engineering.

Sometimes, we face un-educated clients and customers then we will negotiate with them to understanding the requirements in meaningful manner. Because we know very well that without the clarity of the requirements, we will not be able to develop a successful or error free software/system. In software development, requirement engineering works like a bridge that is helpful for the construction the project. It explains what the customer wants, its needs about the developing software system.

In requirement management, many of the activities and steps are performed that are very helpful for the project team to identify the requirements their control on proposed software system their track performance and changing that is most possible throughout the project proceeding.

Overall the requirement management and requirement development are depending on the requirement engineering. If you think that you will develop the software system without the requirement engineering then you fail your project.

Requirement Engineering Process

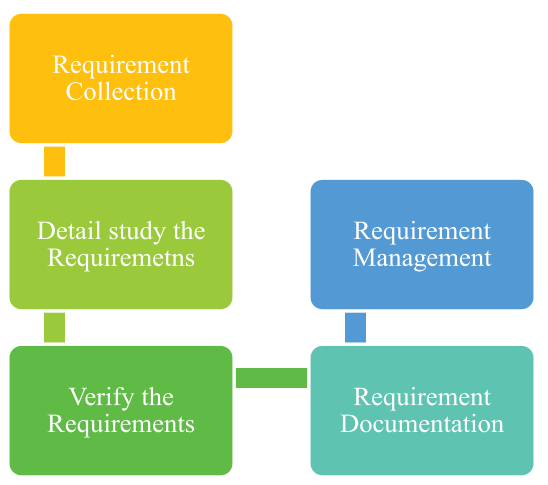

Figure 1: Requirement Engineering Process 


\subsection{Requirement Collection}

In first step of requirement engineering process is the requirement collection or gathering that is collect from the client in different manners. It is basic and most important step for the development of the software system. Software companies gather the requirements from different techniques that is describe in below figure 2 , but these techniques are not limited, many more techniques also use to get the requirements from phone, courier, fax, email and many more.

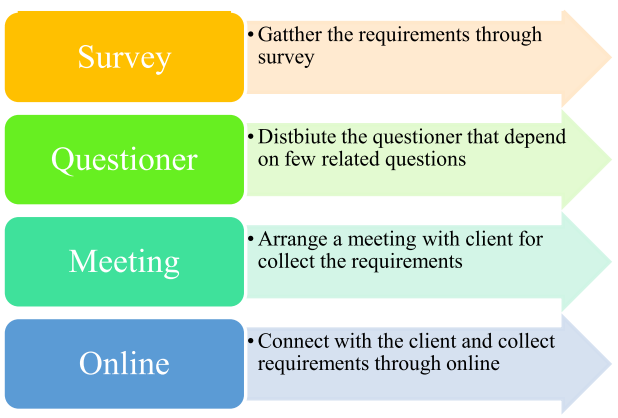

Figure 2: Requirement Gathering Techniques

\subsection{Detail Study the Requirements}

After gathering the requirements, in this phase, analyses the requirement in detail form and will try best to fetch out the relevant and accurate requirements. This phase is most important because on this level we understand the requirements that is much helpful to develop the software system.

\subsection{Verify the Requirements}

After analyzing, verify the requirements and match the actual requirements that is comes from the client. Validate it with different functionality to ensure that requirements are full validated and error free because software system development is based on this validated requirement otherwise a number of problems arises on testing and implementation phase.

\subsection{Requirement Documentation}

The last but not least phase of requirement engineering, all the requirements would be documented that is very beneficial for the software development team. If the requirements are not documented then there are much of errors arises in development phase. Documented requirement also helpful for future changing in the software system.

\subsection{Requirement Management}

Is a set of different activities that help the project team to control, identify and track the requirements because throughout [4] the project proceeding, requirements changing up to the compilation of the software system, Requirement management overall manage the requirement of the proposed software system.

\section{RELATED WORK}

A number of years ago, different scholars and researchers apply different approaches in the filed of software requirement engineering. Currently, no accurate approach gives exact results. Every approach has different results and their meaning that is totally different from one and other.

Sajjad et al. say that use of UML (Unified Modeling Language) diagram, we will efficient the requirement engineering and also their process. Apply the approach [1] on case study (File Sharing System) fetch the requirements, divide into functional and nonfunctional requirements, drafting it with description and give the priority (high, medium, low), mapping the requirements in pre and post condition in use case scenarios. With the help of this technique, we will achieve the efficient requirements for small and low level of project of different companies.

In the software development life cycle, requirement engineering is the most important phase. Abhijit et al. present an approach [2] that is relate with requirement engineering with the help complex system Hospital as a case study. Analyzing different methods of software requirement engineering like OMT method, VORD and Domain Based Approach. Describe the requirement engineering process, starts from the feasibility study to requirement documentation. VORD method of requirement analysis on domain component of a Hospital (patient, bill, nurse, medicine, doctor and etc.) after this evaluate the results in the light of software development life cycle.

In the development of software applications and selection of COTS (Customeroff-the-shelf) components face the different challenges of requirement engineering. 
Sohail et al. discuss several problems [3] in domain of requirement engineering. In framework, highlighted the major challenges that include technology issues and their crises, economical issue, external and internal issue, stakeholders conflicts with one and other. Challenges sub-divided into different problems that is linked and also big challenge for the requirement engineering process. Also describe the requirement engineering process (specification, validation, analyzing, documentation) functional and non-functional requirements and their usage level in proposed software system.

So, finally we can say that a lot of research work done in the field of software requirement engineering and their process.

\section{PROBLEM STATEMENT}

In our software industry, a number of software projects develop day by day. That is good for industries because it is the big investment in our country. Now a days, almost all organizations use different software system for performing routine office tasks and transactions. So, we can say that we face many problems if we don't use and install the software system in any organization and company. Software industry are the big investors for the country and contribute their part in the development of our industries.

With the passage of time, in the development of software system there are many problems that is face by the company in the shape of software requirements. Because requirements express by the clients in their own natural language, that is sometime very difficult to understand. The main issue with this is to illiterate clients. So, they don't say properly and express their requirements about proposed system. Such clients found everywhere [5] to develop the software from the software company. In the result, the proposed software will not be very good in every aspect due to client's unclear requirements. There are many fluctuations arises in software development because there is much gap discussion and communication gap between client and project team. The main reason behind this is the illiterate client as well as not proper clear the requirements.

\section{PROPOSED SOLUTION}

In this section, the proposed solution

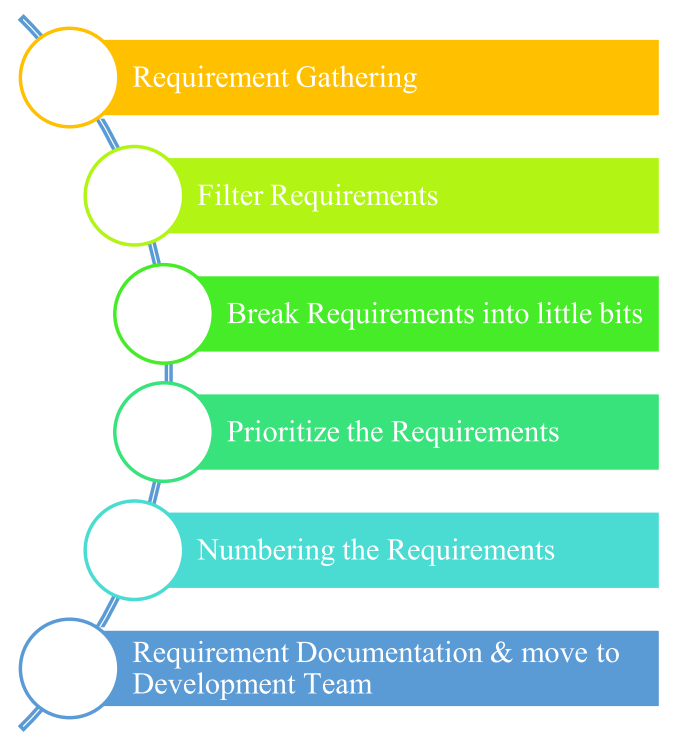

Figure 3: Used Approach

of given problem that is describe in section 3 . Overall description of the proposed solution that how we will develop the software system error free and understandable for the client as well as the company's end user in above figure 3.

\subsection{Requirement Gathering}

In the first stage of given proposed solution, start with requirement gathering. Requirement gather from different sources or techniques that is describe in section I. We know that the client is not well skill or well educated so, we observe the client's company system as well as their employees and very important the end user who directly use the proposed system. Also, we meet the company stakeholders and other employees to exactly find out the requirements of proposed system.

\subsection{Filter the Requirements}

After the requirement gathering, filter the requirements. Requirements divide in functional and non-functional form, sorting them in sequential way and filtered it from fake, ambiguous and irrelevant data.

\subsection{Break the Requirements}

After filtered the requirements, break the requirements in little bit form, break it different parts. Due to this requirement 
specification and analyzing so easy and understandable for the software team.

\subsection{Prioritize the Requirements}

In this phase, prioritize the requirements on the basis of functionality. Essential and basic requirements are on top priority and non-essential requirements are on down priority. Develop the software functionality on priority basis. Client satisfaction is more due to early complete priority requirements.

\subsection{Numbering the Requirements}

The most important step in this approach, allot the numbering to little bit prioritize requirements. Normally numbering will be in numbers form like $1,2,3,4,5,6 \ldots \ldots$. With the help of this, we will easily find out the requirements against their number and work on it in the shape of development.

\subsection{Requirement Documentation}

Last but not least, in this phase, all the requirements will be documented. Requirements will be written that is very helpful to understand the system, track the requirements, all the functionality and their usage and also for future (in the case of changing requirement) After this, document forward to the development team for developing the software system. All the processing must be documented because after the project complete, the documented file sends to the client for understanding all the stages and also its usage and future purpose.

\section{RESULTS}

We use the case study (Hotel Management System) for implement the proposed solution to find out the relevant results.

\subsection{Requirement Gathering}

First of all, in this case study we collect the total 12 requirements that is available in given below table 1 .
Table 1: HMS Requirement Gathering

\begin{tabular}{|l|l|}
\hline User login and password \\
\hline Book room on ID card \\
\hline Check authentication with NADRA \\
\hline Payment through cash/credit card \\
\hline Bank validation \\
\hline External reservation guest \\
\hline Check out/Check in \\
\hline Time scheduling \\
\hline Room cleaning staff \\
\hline Booking confirmation message/email \\
\hline Automated generated slip \\
\hline Food facility record \\
\hline
\end{tabular}

\subsection{Filter the Requirements}

We have total 12 requirements, but after filtering the requirements we erase irrelevant data and divide it into functional and non-functional requirements of Hotel Management System that is given below in tablę2 2: HMS Functional/Non-Functional

\begin{tabular}{|c|c|}
\hline $\begin{array}{l}\text { Functional } \\
\text { Requirements }\end{array}$ & $\begin{array}{l}\text { Non-Functional } \\
\text { Requirements }\end{array}$ \\
\hline $\begin{array}{l}\text { User login and } \\
\text { password }\end{array}$ & $\begin{array}{l}\text { External reservation } \\
\text { guest }\end{array}$ \\
\hline Book room on ID card & $\begin{array}{l}\text { Booking confirmation } \\
\text { message/email }\end{array}$ \\
\hline $\begin{array}{l}\text { Check authentication } \\
\text { with NADRA }\end{array}$ & Room cleaning staff \\
\hline $\begin{array}{l}\text { Payment through } \\
\text { cash/credit card }\end{array}$ & Time scheduling \\
\hline Bank validation & Food facility record \\
\hline Check out/ Check in & ---- \\
\hline $\begin{array}{l}\text { Automated generated } \\
\text { slip }\end{array}$ & ----- \\
\hline
\end{tabular}




\subsection{Break the Requirements}

In this step, we break all the requirements into little bits that is shown in above table 2. But our major focus on functional requirements.

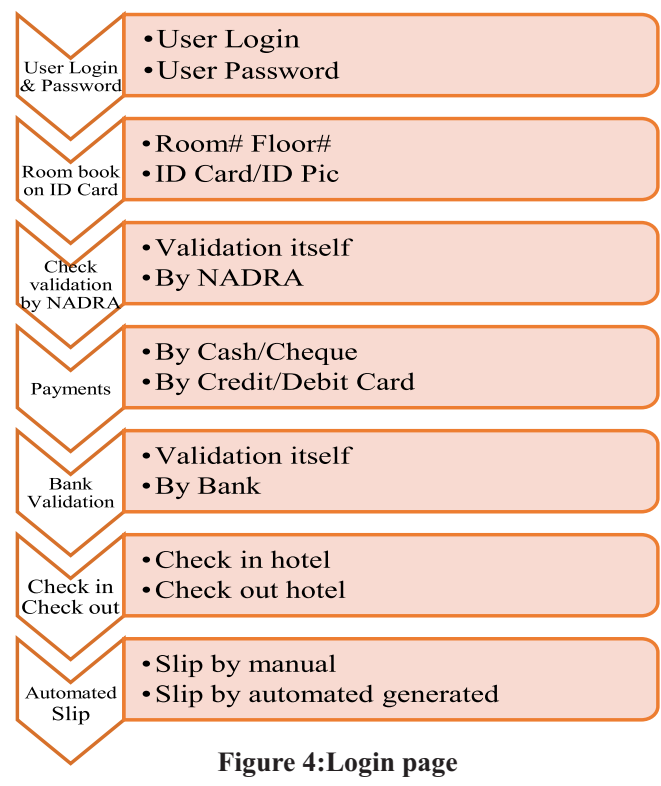

\subsection{Prioritize the Requirements}

In this stage of proposed methodology, we will be prioritizing the 7 functional requirements of HMS (Hotel Management System) that is given above table 2.2.

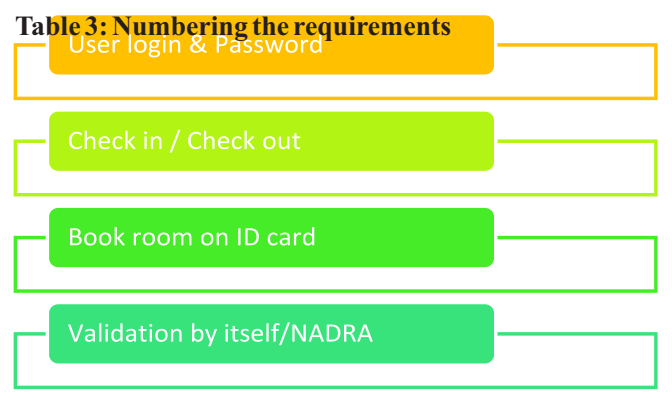

Payments method/Bank validation

Generate the slip

\subsection{Numbering the Requirements}

In the almost last stage of the proposed system that we numbering the functional requirements of the Hotel Management System that is given below in table 3 .

\begin{tabular}{|c|c|}
\hline & Numbering the Requiremei \\
\hline 1 & User Login/Password \\
\hline 2 & Check in/ Check out \\
\hline 3 & Book the room \\
\hline 4 & Validation by NADRA \\
\hline 5 & Payments/Bank checking \\
\hline 6 & Generate Slip \\
\hline
\end{tabular}

\subsection{Requirement Documentation}

In this level, finally we will document all the requirements that is given in table 3 and shift to the development team of Hotel Management software system project.

\section{CONCLUSION}

In this paper, we discuss the overall requirement engineering process and their different levels. We see in our society, a number of software companies working to develop the different software system that is very helpful for the organizations.

In some cases, clients are not welleducated, well-skilled, and illiterate. So, they don't express the clear requirements in front of software team because they don't know what they want with the system.

We present a definite requirement base approach, that describe the clarity of the understandable requirements. Firstly, we gathering the requirements, filtering the requirements, break it into little relevant bits, prioritize it, numbering it and at the end all the requirements would be documented and shift to the development team of software system for construct the project. We implement this proposed methodology on case study (Hotel Management System) that is discuss in section v results.

\section{References}

[1] Muhammad Sajjad Saeed, Nadeem 
Sarwar, Muhammad Bilal. "Efficient Requirement Engineering for Small Scale Project by Using UML", In Sixth International Conference on Innovative Computing Technology (INTECH), 2016.

[2] Abhijit Chakraborty, Mrinal Kanti Baowaly, Ashraful Arefin, Ali Newaz Bahar. "The Role of Requirement Engineering in Software Development Life Cycle", Journal of Emerging Trends in Computing and Information Sciences, vol3(5), May 2012.

[3] Dr. Sohail Asghar, Mahrukh Umar, "Requirement Engineering Challenges in Development of Software Applications and
Selection of Customer-off-the-Shelf (COTS) Components" International Journal of Software Engineering (IJSE), Volume (1), Issue (2), 2010.

[4] Roger S. Pressman, Software Engineering A Practitioner's Approach, 2010.

[5] Lan Sommerville, Software Engineering, 2011. 